\title{
Ejection phase indices of left ventricular performance in infants, children, and adults
}

\author{
Michael Tynan, D. S. Reid, Stewart Hunter, H. H. Kaye, S. Osme, W. Urquhart, and Pat Davies \\ From the Department of Cardiology, Newcastle University Hospitals
}

A validatory study of quantitative single plane left ventricular cineangiography is presented, using human left ventricular casts ranging in size from 1.6 to $135 \mathrm{ml}$. Good correlation was found between actual and calculated volumes $(r=0.967) .62$ patient studies were carried out and the value of the usually calculated indices of left ventricular performance were compared to one another. Ejection fraction and mean rate of circumferential fibre shortening (mean Vcf) were found to be the best discriminators of abnormal left ventricular function, and, on the basis of the presented data, it is suggested that mean Vcf is the more sensitive index of left ventricular performance.

In 1960 Dodge et al. demonstrated the feasibility of calculating left ventricular volumes from biplane angiograms. Since then several groups of workers have elaborated this technique and extended its use to paediatric cardiology (Graham et al., 1971; Miller and Swan, 1964). The technique has also been adapted to single-plane angiocardiography (Green et al., 1967; Herman and Bartle, 1968; Chatterjee et al., 1971; Sandler and Dodge, 1968), but this adaptation has not been adequately validated for left ventricles of small size. Data obtained from left ventricular volume studies, for example left ventricular end-diastolic volume, stroke index, and ejection fraction, are of undoubted value in the assessment of left ventricular performance but lack sensitivity. However, mean Vcf has been proposed as a more sensitive index of left ventricular performance (Karliner et al., 197I). The purposes of this study were twofold: first to investigate the validity of single plane angiocardiography in the estimation of small left ventricular volumes, and secondly to evaluate the clinical usefulness of mean Vcf as an index of left ventricular performance.

\section{Subjects and methods}

I) Validation of left ventricular volume calculations

Polyester resin casts (Trylon resin EM 30r, Tompsett, 1970) were made of 34 human left ventricles obtained at necropsy from patients who died of non-cardiac causes (Fig. I). The fresh hearts were fixed by filling

Received 14 June 1974. the left ventricular cavity with formalin-soaked cotton wool and suspending them in formol saline. No attempt was made to approximate to end-diastolic shape as it was considered unjustifiable to test the model at enddiastole only. Adherent muscle tissue was removed before volume estimations were made. For casts with a volume greater than $15 \mathrm{ml}$, the true volume was determined by water displacement and in the smaller casts by Archimedes principle.

With the casts in a position approximating to the right anterior oblique projection $35-\mathrm{mm}$ cine $x$-rays were taken. For calibration purposes a grid of centimetre squares was $x$-rayed at the position the cast occupied and these films were used to correct for $x$-ray magnification and distortion (Dodge, 1971).

The cast volumes were calculated from these $x$-ray films using the area-length method of Dodge et al. (1960), assuming the left ventricle to be an ellipsoid of revolution. Regression analysis was performed comparing calculated volumes with true volumes using a logarithmic linearizing transformation. The graph thus derived (Fig. 2) was employed to correct the left ventricular volumes calculated from cineangiography in the clinical series.

\section{2) Patient studies}

A total of 62 patients was studied. The volume estimations were made from left ventricular angiocardiograms recorded during the course of clinically indicated cardiac catheterization. The right anterior oblique projection was chosen as it gave the maximum amount of clinical information about mitral valve movement, atrial and ventricular shunting, and mitral-aortic relations. The film speeds were either 44 or 64 frames/second. When the left heart was not entered, a pulmonary artery injection was performed. Left ventricular end-systolic and 


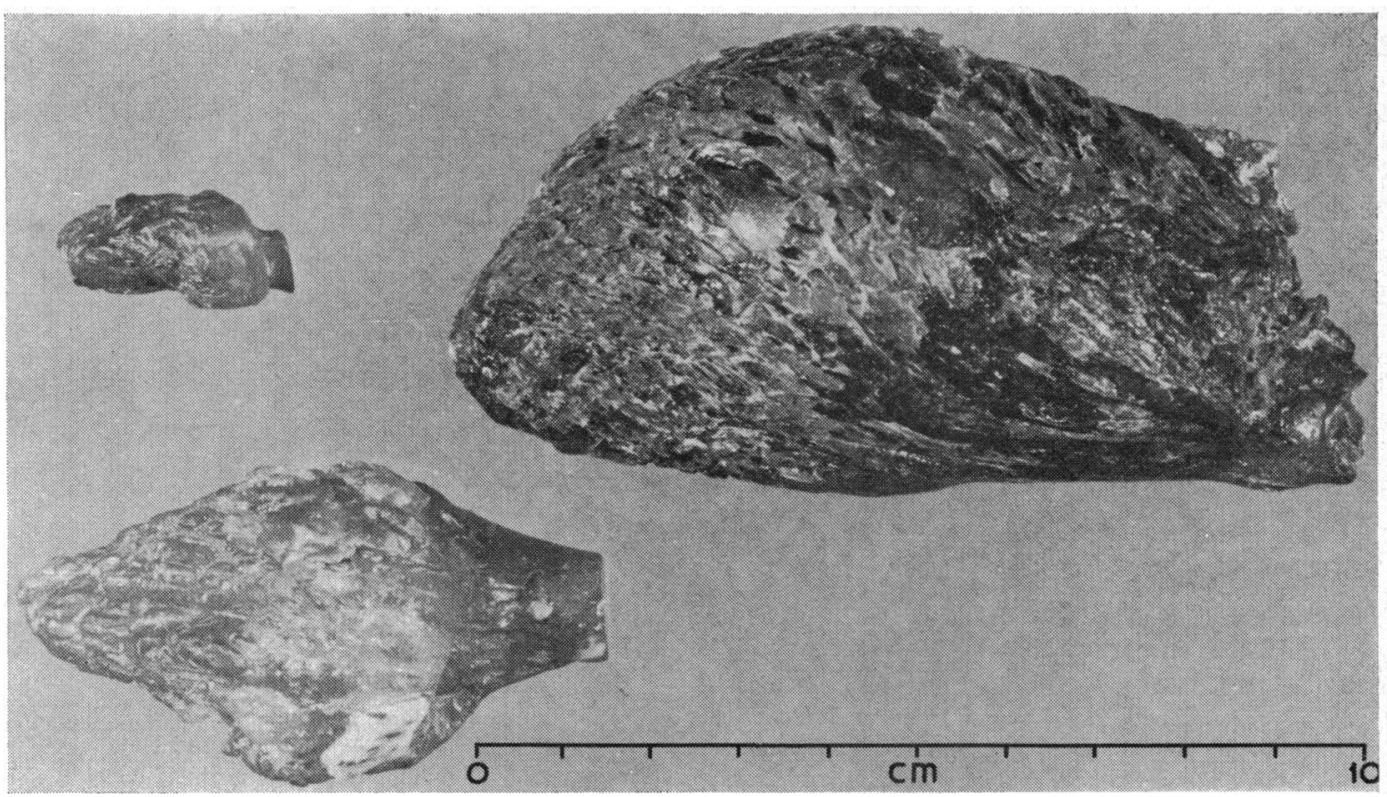

FIG. I Polyester resin casts of human left ventricles of varying size.

end-diastolic volumes were calculated using the arealength method. Post-ectopic beats were excluded and no cycle later than the third following left ventricular opacification was used (Karliner, Bouchard, and Gault, 1972). At the end of each study the centimetre squares grid was filmed at the height of the apex beat, using the same tube-to-film distance as in the patient study. Corrections were made for magnification and distortion as described above. The volumes thus derived were corrected to 'true' volume using the graph shown in Fig. 2. Ejection fraction was calculated in the usual way using the corrected values of end-diastolic and end-systolic volume. Mean Vcf was calculated from:

\section{EDD-ESD \\ $\overline{\mathrm{EDD} \times \mathrm{ET}}$}

where EDD is the end-diastolic cavity diameter measured at the mid-point of the longest long axis, ESD is the end-systolic cavity diameter measured similarly at end-systole; and ET is the ejection time obtained from the number of frames during ventricular contraction divided by the film speed (Karliner et al., I97I).

The patients were classified as follows.

a) No left ventricular disease There were 16 patients in this category. Ages ranged from 7 months to 54 years (mean age II years, Io months). Diagnoses included pulmonary valve stenosis with right ventricular to pulmonary artery systolic pressure differences of less than $60 \mathrm{mmHg}$ (8 $\mathrm{kPa}$ ) (5 patients); ventricular septal defect with pulmonary-systemic flow ratio of less than I.5/I (2 patients); chest pain but with normal coronary angiograms ( 2 patients); systolic murmurs for which no structural cause was found (2 patients); vascular ring (I patient); coarctation of aorta with systolic pressure difference of $20 \mathrm{mmHg}(2.67 \mathrm{kPa})$ and normal upper limb blood pressures (I patient); persistent systolic murmur following closure of persistent ductus arteriosus (I patient); postoperative pulmonary valve stenosis without residual pressure gradient (I patient), and I patient investigated to exclude structural causes for paroxysmal ventricular tachycardia.

b) Primary heart muscle disease in childhood There were 8 patients in this category, with ages ranging from $I$ day to 9 years (mean age 2 years, 8 months). They all had the clinical syndrome of endocardial fibroelastosis without obstructive lesions such as aortic valve stenosis or coarctation of the aorta.

c) Left ventricular pressure overload There were 9 patients in this group ranging in age from I week to I4 years (mean age 4 years, 3 months). Diagnoses included coarctation of aorta (4 patients) and significant aortic valve stenosis ( 5 patients).

d) Left ventricular volume overload There were 23 patients in this group, with ages ranging from 6 weeks to 63 years (mean age 5 years 3 months). Diagnoses included congenital ventricular septal defect (ro patients), acquired ventricular septal defect (I patient), persistent ductus arteriosus (I I patients), and aortic valve incompetence ( $I$ patient).

e) Ischaemic heart disease There were 6 patients in this group, with ages ranging from 41 to 46 years (mean age 43 years). In none of these was there any evidence of dyskinetic left ventricular contraction. 
All measurements of left ventricular volume were expressed per square metre of body surface area.

The object of the study was to examine the ability of end-diastolic volume $/ \mathrm{m}^{2}$, end-systolic volume $/ \mathrm{m}^{2}$, stroke index, ejection fraction, and mean Vcf to discriminate between normal and abnormal left ventricular function, i.e. primary heart muscle disease in childhood, and compare them to the group with no left ventricular disease. The other groups of patients were used to provide a wide range of left ventricular function in order to test the hypothesis that mean Vcf was the most sensitive of all these indices in the assessment of left ventricular function. Statistical methods used were Student's ' $t$ ' test, the null hypothesis being retained when its probability exceeded 0.05 .

\section{Results}

\section{a) Validatory study}

The actual volumes of the casts ranged from $1.6 \mathrm{ml}$ to $135 \mathrm{ml}$. The regression analysis described above revealed a correlation coefficient of 0.967 (Fig. 2) and the regression equation was:

Volume true $=0.59(\text { Volume estimated })^{1.09}$

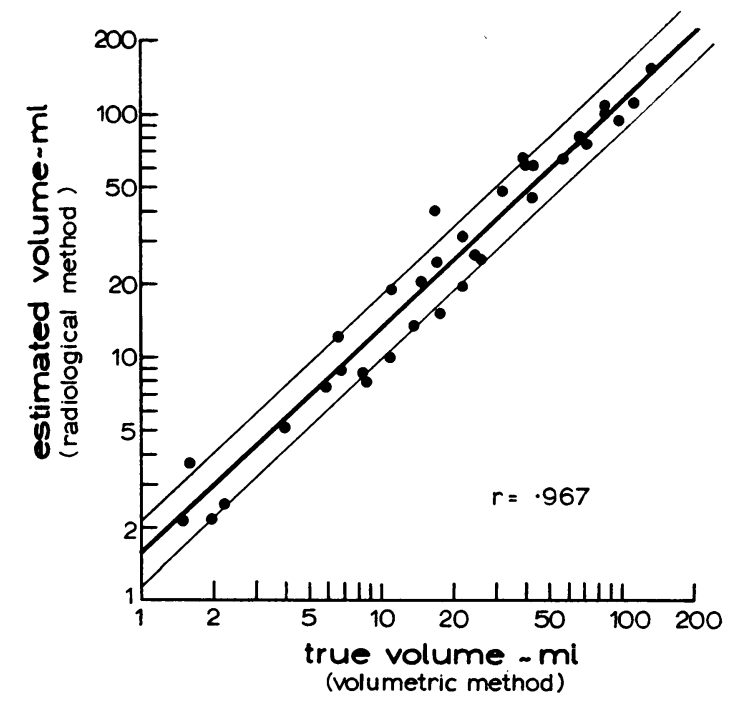

FIG. 2 Regression analysis relating estimated to true volume of casts.

TABLE I Patients without structural disease of left ventricle and those with primary heart muscle disease

\begin{tabular}{|c|c|c|c|c|c|}
\hline Case & $\begin{array}{l}\text { End-diastolic } \\
\text { volume }\left(\mathrm{ml} / \mathrm{m}^{2}\right)\end{array}$ & $\begin{array}{l}\text { End-systolic } \\
\text { volume }\left(\mathrm{ml} / \mathrm{m}^{2}\right)\end{array}$ & $\begin{array}{l}\text { Stroke volume } \\
\left(\mathrm{ml} / \mathrm{m}^{2}\right)\end{array}$ & Ejection fraction & $\begin{array}{l}\text { Mean } V c f \\
(\text { circs/s) }\end{array}$ \\
\hline \multicolumn{6}{|l|}{ Normal } \\
\hline I & 44.0 & 13.0 & 31.0 & 0.70 & I.6I \\
\hline 2 & 64.0 & 14.0 & 50.0 & 0.78 & 1.62 \\
\hline 3 & 73.0 & 14.0 & 59.0 & $0.8 \mathrm{I}$ & 1.71 \\
\hline 4 & 70.5 & 20.5 & 50.0 & 0.71 & 1.39 \\
\hline 5 & 41.6 & 15.3 & 26.3 & 0.63 & 1.14 \\
\hline 6 & 51.0 & 12.0 & 39.0 & 0.76 & 1.63 \\
\hline 7 & 84.0 & 24.0 & 60.0 & 0.71 & 1.12 \\
\hline 8 & 75.0 & 21.5 & 53.5 & 0.71 & 1.66 \\
\hline 9 & 87.0 & 27.0 & 60.0 & 0.69 & 1.67 \\
\hline ro & 97.0 & 35.0 & 62.0 & 0.64 & 1.07 \\
\hline II & 87.0 & 24.0 & 63.0 & 0.72 & 1.42 \\
\hline 12 & 69.0 & 10.0 & 59.0 & 0.71 & 1.22 \\
\hline 13 & 91.0 & 35.0 & 56.0 & 0.62 & 1.17 \\
\hline 14 & 102.0 & 16.0 & 86.0 & 0.84 & 1.19 \\
\hline 15 & 96.0 & 21.0 & 75.0 & 0.78 & 1.25 \\
\hline 16 & 97.0 & 30.0 & 67.0 & 0.69 & 1.60 \\
\hline Mean & 76.8 & 20.8 & 56.1 & 0.72 & 1.40 \\
\hline$S D \pm$ & 19.2 & 8.0 & 15.0 & 0.06 & 0.24 \\
\hline \multicolumn{6}{|c|}{$\begin{array}{l}\text { Primary heart muscle } \\
\text { disease }\end{array}$} \\
\hline I & 35.0 & 22.5 & 12.5 & 0.36 & $0.4 \mathrm{I}$ \\
\hline 2 & 19.0 & 18.0 & 1.0 & 0.07 & 0.23 \\
\hline 3 & 165.0 & I 19.0 & 46.0 & 0.28 & 0.39 \\
\hline 4 & 85.0 & 53.5 & 31.5 & 0.37 & 0.81 \\
\hline 5 & 147.0 & 121.0 & 26.0 & 0.18 & 0.10 \\
\hline 6 & 49.0 & 22.0 & 27.0 & 0.55 & 0.90 \\
\hline 7 & 190.0 & 142.0 & 48.5 & 0.25 & 0.40 \\
\hline 8 & 227.0 & 203.0 & 24.0 & 0.11 & 0.07 \\
\hline Mean & II4.6 & 87.6 & 27.1 & 0.27 & $0.4 \mathrm{I}$ \\
\hline$S D \pm$ & 78.0 & 68.6 & 15.8 & 0.16 & 0.30 \\
\hline
\end{tabular}


The standard deviation about the regression corresponds to a range in the final estimate of actual volume of $\times 1.4$ to $\times 0.72$.

\section{b) Subjects}

The results in the normal group and the group with primary heart muscle disease are presented in Table $\mathrm{I}$. When end-diastolic volume $/ \mathrm{m}^{2}$ was compared in the two groups, there was no statistically significant difference $(P>0.1)$. However, endsystolic volume $/ \mathrm{m}^{2}$ was significantly smaller in the normal group than in the group with primary heart muscle disease $(P<0.05)$. Stroke index, too, was significantly less in the group with primary heart muscle disease than in the normals $(P<0.001)$. There was, however, considerable overlap of values for end-systolic volume $/ \mathrm{m}^{2}$ and stroke index between the two groups, making it impossible to separate completely the known normal from the known abnormal left ventricles. Ejection fraction distinguished the two groups in a statistically significant way $(P<0.001)$ and none of the patients with primary heart muscle disease had a normal ejection fraction (Fig. 3). Similarly, mean Vcf showed good statistical discrimination between the two groups $(P<0.00 \mathrm{I})$ and no patient with primary heart

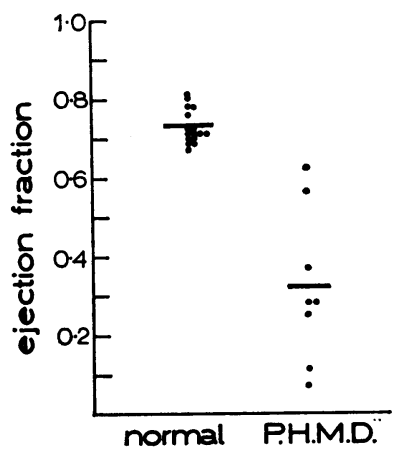

FIG. 3 Comparison of ejection fraction in normal left ventricles and primary heart muscle disease (PHMD). muscle disease had a normal mean Vcf (Fig. 4). The group data obtained from patients with left ventricular pressure overload, left ventricular overload, and ischaemic heart disease are shown in Table 2. In all three groups there was a wide scatter of left ventricular function as judged by ejection fraction and mean Vcf, the range being from the grossly limited to the normal.

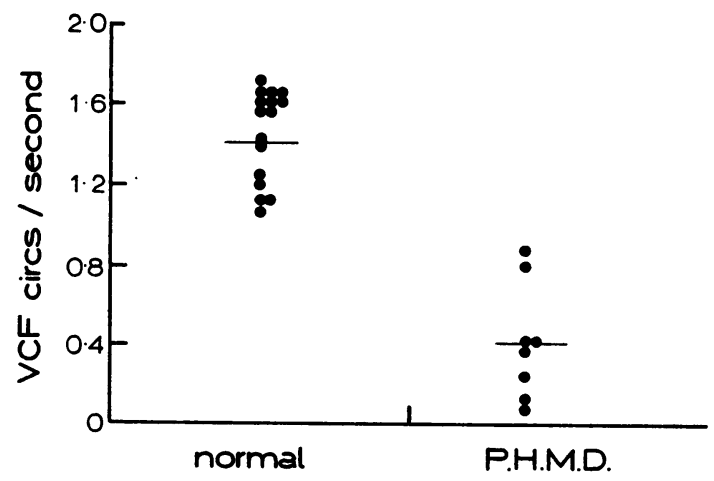

FIG. 4 Comparison of mean Vcf in normal left ventricles and primary heart muscle disease (PHMD).

In Fig. 5 we have compared ejection fraction on the vertical axis and mean Vcf on the horizontal axis, for all the patients in this series with structural or functional left heart abnormalities. (Patients with no left ventricular disease are omitted.) The interrupted lines represent the lower limit of normal for ejection fraction (0.59), obtained from the literature (Graham et al., 197I), and the lower limit of normal for mean Vcf (r.07), taken as the lowest value found in the group with no left ventricular disease in the present series. All the patients who had a diminished ejection fraction also had a diminished mean Vcf. Eight patients with normal ejection fraction had diminished mean Vcf but there were no patients in the present series in whom ejection fraction was diminished and mean Vcf was normal.

TABLE 2 Group data from patients with left ventricular pressure overload, left ventricular volume overload, and ischaemic heart disease

\begin{tabular}{|c|c|c|c|c|c|c|}
\hline & & $\begin{array}{l}\text { End-diastolic } \\
\text { volume }\left(\mathrm{ml} / \mathrm{m}^{2}\right)\end{array}$ & $\begin{array}{l}\text { End-systolic } \\
\text { volume }\left(\mathrm{ml} / \mathrm{m}^{2}\right)\end{array}$ & $\begin{array}{l}\text { Stroke volume } \\
\left(\mathrm{ml} / \mathrm{m}^{2}\right)\end{array}$ & Ejection fraction & $\begin{array}{l}\text { Mean Vcf } \\
(\text { circs/s) }\end{array}$ \\
\hline $\begin{array}{l}\text { Pressure overload } \\
(N=9) \\
\text { Volume overload } \\
(N=23) \\
\text { Ischaemic heart disease } \\
(N=6)\end{array}$ & $\begin{array}{l}\text { Mean } \\
\text { SD } \\
\text { Mean } \\
\text { SD } \\
\text { Mean } \\
\text { SD }\end{array}$ & $\begin{aligned} & 53.9 \\
& \pm 35.0 \\
& 110.9 \\
& \pm 58.7 \\
& 108.7 \\
& \pm 32.8\end{aligned}$ & $\begin{array}{r}16.5 \\
\pm 9.6 \\
34.1 \\
\pm 20.2 \\
42.0 \\
\pm 19.9\end{array}$ & $\begin{array}{r}37.3 \\
\pm 29.7 \\
76.8 \\
\pm 40.9 \\
66.7 \\
\pm 20.0\end{array}$ & $\begin{array}{r}0.65 \\
\pm 0.15 \\
0.69 \\
\pm 0.07 \\
0.62 \\
\pm 0.10\end{array}$ & $\begin{array}{r}1.24 \\
\pm 0.46 \\
1.36 \\
\pm 0.41 \\
1.02 \\
\pm 0.22\end{array}$ \\
\hline
\end{tabular}




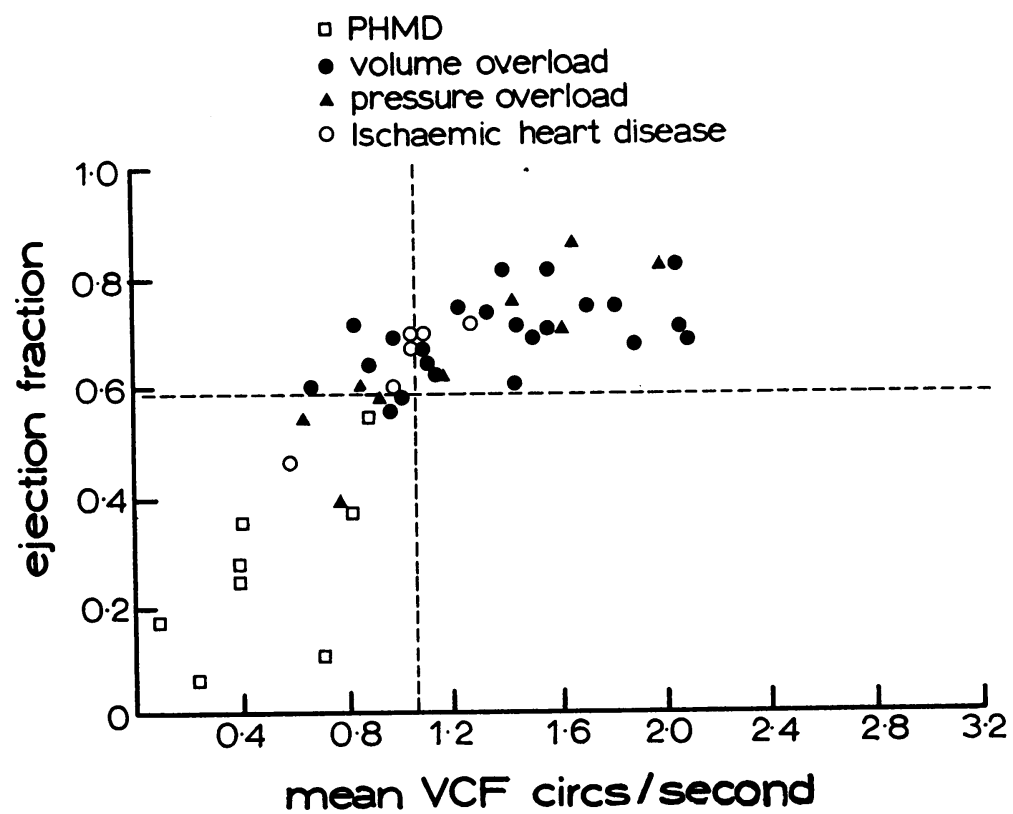

FIG. 5 Comparison of ejection fraction and mean Vcf in primary heart muscle disease (PHMD), volume overload, pressure overload, and ischaemic heart disease.

\section{Discussion}

Although single plane right anterior oblique cineangiocardiography has been used and validated for the left ventricular volume estimations in adults, these studies have not included the very small left ventricular volumes encountered in infants. Graham et al. (1971) have described the use of biplane cineangiography in children with particular reference to this group and found that the relation between the actual and the calculated volumes was not rectilinear. They got over this difficulty by proposing 2 regression lines, one for left ventricular volumes over $15 \mathrm{ml}$ and one for those under $15 \mathrm{ml}$. Rather than assume a discrete break in the line, our approach has been to correct for non-linearity by the use of a linear transformation. The $\log / \log$ relation between the two estimates appears empirically to offer a satisfactory solution and has the additional advantage of giving a uniform variance about the best fit line which can be translated into percentage error. Our validation study has two main advantages. Firstly, the use of solid casts allows optimal accuracy both in the measurement of actual volumes and in positioning for angiography, and secondly in contrast to previous similar validation studies, in this series only human left ventricles were used.

Although the results presented show a good rela- tion between actual and calculated left ventricular volumes, the wide standard deviation suggests that the results obtained when using single plane cineangiography must be interpreted with caution. When the present series is compared with other series (Green et al., 1967; Chatterjee et al., 1971), the limits of accuracy are remarkably similar, bearing in mind that we have used a $\log / \log$ transformation and that other workers have not (Green et al., 1967; Chatterjee et al., 1971; Herman and Bartle, I968). However, when the results of quantitative angiography are not expressed as absolute values, but as ratios of values obtained from the same patient, e.g. ejection fraction or mean Vcf, these measurements can be used with greater confidence. The ejection fraction and mean Vcf values obtained from patients with a wide variety of cardiac abnormalities and levels of left ventricular function show that all patients with reduced ejection fraction had a reduction in mean Vcf, and that taken together these measurements are good indicators of severe limitation of left ventricular performance. End-diastolic volume $/ \mathrm{m}^{2}$, end-systolic volume $/ \mathrm{m}^{2}$, and stroke index, on the other hand, did not provide complete separation between the normal group and the group with primary heart muscle disease. There were 8 patients in whom the mean Vcf was depressed but the ejection fraction was normal. In no case was the ejection fraction depressed in the presence of a normal 
mean Vcf, suggesting that the introduction of a measurement of velocity of contraction may make it possible to detect milder abnormalities of left ventricular performance than can be detected by ejection fraction alone. The data we present here support the statement of Karliner et al. (I97I) that mean Vcf separated normal from abnormal left ventricular function, when normality and abnormality had been determined by measurements of instantaneous tension - velocity - length relations (Gault, Ross, and Braunwald, 1968). In the isolated supported dog heart the rate of left ventricular wall shortening is sensitive to acute changes in preload and afterload (Burns, Covell, and Ross, 1973). In the intact dog, on the other hand, little change in rate of shortening is seen in response to acute or chronic changes in preload (Covell et al., 1973; Ross and McCullagh, 1972), but the inverse relation of velocity of shortening to acute changes in afterload is still seen (Bove and Lynch, 1970). Ross, Covell, and Mahler (1974) suggested that hypertrophy, change in left ventricular shape, and recruitment of all sarcomeres to an increased fibre length on the ascending limb of the Starling curve are the mechanisms of adaptation to a chronic volume overload. These mechanisms occur leaving the inotropic state of the myocardium and, therefore, the Vcf relatively unimpaired. Only when these compensatory mechanisms have been exhausted will the rate of wall shortening fall, either due to deterioration in left ventricular inotropic state or in response to an increase in afterload. In either event, a decrease in mean Vcf indicates that the limit of preload adjustment has been reached. The sensitivity of mean Vcf to changes in afterload will not, therefore, invalidate it as an index of left ventricular performance, when left ventricular afterload is within the normal range. But, if there is increased left ventricular afterload, a reduction in mean Vcf may theoretically suggest impaired left ventricular performance when the inotropic state is unimpaired. However, in this series mean Vcf showed a similar distribution in the patients with pressure overload as in those with volume overload $(P>0 . I)$, suggesting that mean Vcf may be equally valid in both groups.

The use of the mean Vcf as an index of left ventricular performance is attractive because it employs only one assumption about left ventricular geometry, namely that the left ventricle has a circular cross-section. Also, unlike those isovolumic phase indices which have been derived from the application of muscle mechanics to the intact human heart, mean Vcf is not dependent on any model of muscle contraction (Pollack, 1970), nor does it require any extrapolation of data (van den Bos et al., 1973).
Furthermore, it does study the phase of left ventricular contraction which is of most clinical interest.

In conclusion, this study demonstrates that quantitative left ventricular angiography using single plane cine is as applicable to infants and children as it is to adults. We suggest that mean Vcf is a sensitive, clinically applicable indicator of left ventricular function and when taken in conjunction with ejection fraction provides very useful information about left ventricular myocardial performance. It is particularly applicable to patients with congenital heart disease where measurements are rarely influenced by dyskinetic areas of myocardium. The measurements proposed can easily be obtained in any routine cardiac catheterization laboratory, as they require only careful examination of two frames of the cineangiogram and knowledge of the ejection time.

\section{References}

Bove, A. A., and Lynch, P. R. (1970). Radiographic determination of force-velocity-length relationship in the intact dog heart. Fournal of Applied Physiology, 29, 884.

Burns, J. W., Covell, J. W., and Ross, J., Jr. (1973). The mechanics of isotonic left ventricular contractions. American fournal of Physiology, 224, 725.

Chatterjee, K., Sacoor, M., Sutton, G. C., and Miller, G. A. H. (1971). Assessment of left ventricular function by single plane cine-angiographic volume analysis. British Heart fournal, 33, 565.

Covell, J. W., Mahler, F., O'Rourke, R. O., and Ross, J., Jr. (1973). Velocity of left ventricular fiber shortening during acute loading and altered contractility in the conscious dog. Circulation, 48, Suppl. IV, 66.

Dodge, H. T. (197I). Determination of left ventricular volume and mass. Radiologic Clinics of North America, 9, 459.

Dodge, H. T., Sandler, H., Ballew, D. W., and Lord, J. D. (1960). Use of biplane angiocardiography for the measurement of left ventricular volume in man. American Heart fournal, 60, 762 .

Gault, J. H., Ross, J., Jr., and Braunwald, E. (I968). Contractile state of the left ventricle in man: instantaneous tension-velocity-length relations in patients with and without disease of the left ventricular myocardium. Circulation Research, 22, $45 \mathrm{I}$.

Graham, T. P., Jarmakani, J. M., Canent, R. V., and Morrow, M. N. (I97I). Left heart volume estimation in infancy and childhood. Circulation, 43, 895.

Green, D. G., Carlisle, R., Grant, C., and Bunnell, I. L. (1967). Estimation of left ventricular volume by oneplane cine-angiography. Circulation, 35, 61.

Herman, H. J., and Bartle, S. H. (1968). Left ventricular volumes by angiocardiography: comparison of methods and simplification of techniques. Cardiovascular Research, 2, 404 .

Karliner, J. S., Bouchard, R. J., and Gault, J. H. (1972). Haemodynamic effects of angiographic contrast material in man: a beat-by-beat analysis. British Heart fournal, 34, 347.

Karliner, J. S., Gault, J. H., Eckberg, D., Mullins, C. B., and Ross, J., Jr. (1971). Mean velocity of fiber shortening: a simplified measure of left ventricular myocardial contractility. Circulation, 44, 323. 
Miller, G. A. H., and Swan, H. J. C. (1964). Effect of chronic pressure and volume overload on left heart volumes in subjects with congenital heart disease. Circulation, 30, 205.

Pollack, G. H. (1970). Maximum velocity as in index of contractility in cardiac muscle: a critical evaluation. Circulation Research, 26, III.

Ross, J., Jr., Covell, J. W., and Mahler, F. (1974). Contractile responses of the left ventricle to acute and chronic stress. European fournal of Cardiology, 1, 325.

Ross, J., Jr., and McCullagh, W. H. (1972). The nature of enhanced performance of the dilated left ventricle in the dog during chronic volume overloading. Circulation Research, 30, 549.
Sandler, H., and Dodge, H. T. (1968). The use of single plane angiocardiograms for the calculation of left ventricular volume in man. American Heart fournal, 75, 325.

Tompsett, D. H. (1970). Anatomical Techniques. Livingstone, Edinburgh and London.

Van den Bos, G. C., Elzinga, G., Westerhof, N., and Noble, M. I. M. (1973). Problems in the use of indices of myocardial contractility. Cardiovascular Research, 7, 834.

Requests for reprints to Dr. Michael Tynan, Department of Cardiology, Newcastle General Hospital, Westgate Road, Newcastle on Tyne NE4 6BE. 